\title{
Biochemical

\section{Highly sensitive gold nanoparticle based electrochemical biosensor for detection of Antigen antibody interactions}

\author{
Anita Rawat ${ }^{1}$, K. P. Singh ${ }^{1}$, Pashupat Vasmatkar ${ }^{* 2}$ and Pratibha Baral ${ }^{2}$ \\ ${ }^{1}$ Nanobiosensor Research Laboratory, Biophysics Unit, \\ ${ }^{2}$ Department of Biochemistry, College of Basic Sciences and Humanities, G. B Pant University of Agriculture \\ and Technology, Uttarakhand-263145, India
}

\begin{abstract}
The electrochemical biosensor was designed for label-free detection of bovine serum albumin (BSA). In the developed electrochemical sensor gold coated polycarbonate membrane of different 30, 50 and $100 \mathrm{~nm}$ pore sizes. were used for detection. The gold coated polycarbonate membranes were thiolated by 16-Mercaptohexadecanoic acid (MHDA) and then activated by 1-ethyl-3-(3-dimethylaminopropyl)-carbodiimide (EDC) and N-Hydroxysuccinimide (NHS) for the binding of the antibody (BSA). After activation of the membranes, the BSA antibody was immobilized and the membranes were subjected to the detection of BSA antigen with the help of a homemade electrochemical setup. The specificity of the antibody was cross-checked with a non-corresponding Prostate Specific Antigen (PSA). The specificity and sensitivity of the designed biosensor along with the signal amplification due to binding of antigen-gold nanoparticle conjugate was also determined. The impedance corresponding to each step of membrane modification was observed and it was found that there was a sharp increase in the measured impedance from modification to detection. Also, there was multiple fold increase in signal due to tagging of GNP. The impedance corresponding to different pore sized membranes was used to find a suitable pored membrane for the sensitive detection and it was observed that 30 $\mathrm{nm}$ pore size membrane showed comparatively better result than 50 and $100 \mathrm{~nm}$ pore size membrane.
\end{abstract}

KEY WORDS: NANOPARTICLE, IMMUNOASSAY, ELECTROCHEMICAL BIOSENSOR, ANTIGEN-ANTIBODY

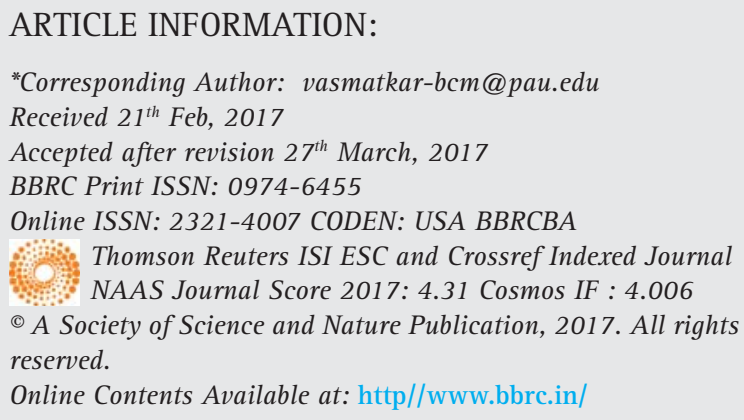




\section{INTRODUCTION}

Since the development of the first glucose biosensor by Clark in 1962. Electrochemical biosensors have been of great interest because of the properties like simple instrumentation, low cost, rapid and sensitive response (Lin et al., 2005, Grieshaber et al., 2008). Recently, the emergence of nanoparticles helped in improving the performance of electrochemical sensors. Some particular nanomaterials, such as gold and semiconductor quantum-dot nanoparticles, have already been widely used.

Biosensors are being developed by integrating functional biomolecules with different types of nanomaterials, including metallic nanoparticles, semiconductor nanoparticles, magnetic nanoparticles, inorganic/ organic hybrid, dendrimers, and carbon nanotubes/ grapheme (Singh, 2011). Many biomolecules including proteins/enzymes/oligo-peptides (Shen et al., 2003, Crespilho et al., 2009), antibody/antigens (Haes et al., 2004, Pengo et al., 2007), biotin/streptavidin (Zhu et al., 2008) and DNA/oligonucleotides/aptamers (Nykypanchuk et al., 2008) have been immobilized on the surface of nanoparticles to form noble metal nanoparticle-biomolecule conjugates which are then used for biosensing (Willner et al., 2007, Guo and Dong, 2009, Li et al., 2010, Song et al., 2010) . Gold nanoparticles (AuNP) are widely used due to their biocompatibility, high surface to volume ratio, conductivity and catalytic properties (Wang et al., 2002, Azzazy et al., 2009). AuNPs are employed for signal amplification (Cao et al., 2011), as a label in bioanalytical devices (Omidfar et al., 2013) especially in the case of optical and electrochemical detection method.

Biosensors based on the selective and specific binding properties of antigen and antibody are known as immunosensors. The basic principle of immunosensors is the specificity of the molecular recognition of antigens by antibodies to form a stable complex. The sensitive and selective binding nature of antigen and antibody is very useful in various applications such as medical detection, processing quality control, and environmental monitoring (Tang et al., 2002).

Recently different electrochemical immunosensors have been developed for selective detection of proteins, pathogens or toxins such as aflatoxin M1 (Vig et al., 2009), enrofloxacin (Wu et al., 2009), prostate specific antigen (Wang et al., 2012), pathogenic Staphylococcus aureus ATCC25923 (Braiek et al., 2012).

This study of gold nanoparticle-based electrochemical biosensors for antibody-antibody interaction aims to compare the detection performances of different pore sized gold coated polycarbonate membrane. Here a simple low-cost electrochemical set-up was prepared to measure the change in impedance on antigen-antibody interactions and also to measure the effect of gold nanoparticle and antigen conjugate in signal amplification.

\section{MATERIALS AND METHODS}

\section{PREPARATION OF GOLD NANOPARTICLES}

Synthesis of AuNPs of $20 \mathrm{~nm}$ was carried out according to the procedures described by Turkevich et al., (1951). In brief, $50 \mathrm{ml}$ of $1.0 \mathrm{mM} \mathrm{HAuCl}_{4}$ was boiled with vigorous stirring for 15-20 minutes. On boiling, $5 \mathrm{ml}$ of 1\% trisodium citrate was quickly added. Solution changes its color from clear to dark blue and then to deep red. The heat was turned off after 10-15 min, but stirring was continued for 10 minutes. The prepared gold nanoparticle suspension was cooled, filtered and stored in a dark bottle at $4^{\circ} \mathrm{C}$.

\section{BIOPHYSICAL CHARACTERIZATION OF GOLD NANOPARTICLES}

UV-visible characterization of the AuNP suspension was performed using a UV-Visible spectrophotometer (Lin et al., 2007). The absorbance measurements were made over the wavelength range of 250-700 $\mathrm{nm}$ using $1 \mathrm{~cm}$ path length quartz cuvette.

\section{COUPLING OF ANTIGEN (BSA) WITH AUNP}

For coupling of antigen with the citrate-stabilized AuNPs, first $900 \mu \mathrm{l}$ of AuNP suspension (dilution 1:10) was mixed with $100 \mu \mathrm{l}$ of $1 \mathrm{mM}$ MHDA solution and incubated for $30 \mathrm{~min}$ a shaker. Afterward, the solution was centrifuged at $10,000 \mathrm{rpm}$ at $4^{\circ} \mathrm{C}$ for 20 minutes and resuspended in $500 \mu \mathrm{l}$ of sodium phosphate buffer. Afterward, $10 \mu \mathrm{g} / \mathrm{ml}$ suspension of antigen (BSA) was added, and the solution was further incubated for 30 min under rotation. Then the solution was made up to $1 \mathrm{ml}$ with PBS buffer and centrifuged at $12000 \mathrm{rpm}$ at $4^{\circ} \mathrm{C}$ for 1 hour, and was finally resuspended in sodium phosphate buffer (Kleo et al., 2012).

\section{MODIFICATION OF GOLD COATED POLYCARBONATE TRACK ETCH (PCTE) MEMBRANE}

The PCTE membrane of different pore size (30, 50 and $100 \mathrm{~nm}$ ) was coated by gold through sputter coating. Each membrane was then subjected to surface modification (Chen et al., 2008). Firstly, gold coated polycarbonate membrane is thiolated by immersing it in an ethanol solution of $1 \mathrm{Mm}$ 16-mercaptohexadecanoic acid (MHDA) for 24 hours to form self-assembled monolayer and then activated by immersing in a $75 \mathrm{mM}$ solution of 
1-ethyl-3-(3-dimethylaminopropyl) carbodiimide (EDC) and $15 \mathrm{mM}$ solution of N-hydroxysuccinimide (NHS) for 1 hour to convert carboxylic group to an active NHS ester. After the reaction, the membrane was rinsed with de-ionised water. Immobilization of antibody was done by $1 \mathrm{mg} / \mathrm{ml}$ anti-BSA Antibody solution prepared

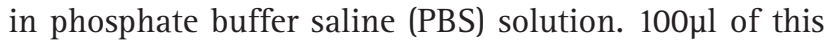
solution was added on the thiolated membrane and stored at room temperature for 1 hour and then rinsed with PBS solution for removing excess antibody. 100 $\mu \mathrm{l}$ of antigen BSA is applied on antibody immobilized gold coated membrane for 1 hour. The membrane was mounted in the glass cell for measuring the change in impedance after each step of surface modification.

\section{CHARACTERIZATION OF MODIFIED MEMBRANE}

Characterization of polycarbonate membrane was performed by Fourier Transform Infrared Spectroscopy (FTIR) after each step of membrane's surface modification by simply putting the dry membrane in a sample holder.

\section{FABRICATION OF MEMBRANE BASED ELECTROCHEMICAL BIOSENSOR}

The electronic circuit designed in the laboratory is shown in figure 3.1 while the original photograph of the system is also depicted in figure 3.2. Electrochemical measurements were carried out at room temperature in a cell with two $\mathrm{Ag} / \mathrm{Ag}-\mathrm{Cl}$ electrodes (with a surface area of $1 \mathrm{~cm}^{2}$ ) and a working volume of $6 \mathrm{ml}$ divided in two L-shaped glass cell by the membrane.

The change in the potential was recorded as a function of time using the digital multimeter (in volts) after each step of membrane modification impedance was calculated by the given formula:

$$
\text { Impedance, } Z=\frac{\left(\text { Applied Potential }- \text { Potential }_{\text {voltmeter }}\right) \times \text { Resistance }}{\text { Potential }_{\text {voltmeter }}}
$$

\section{RESULTS AND DISCUSSION}

\section{CHARACTERIZATION OF GOLD NANOPARTICLES}

The peak obtained at $516 \mathrm{~nm}$ (Fig. 2) depicts that the size of nanoparticles ranges from $5-15 \mathrm{~nm}$..

\section{CHARACTERIZATION OF MODIFIED GOLD COATED MEMBRANE}

The FTIR spectra of PCTE membrane recorded on the computer using OMNIC software (Figure 3). The sample (membrane) was fitted into membrane sized hole in the sample holder. After placing membrane between the light filters of the instrument, IR rays interact with the sample and yield various types of stretching, bending and vibrations forming a spectrum.

Various FTIR peaks of $\mathrm{Ag}-\mathrm{Ab}$ immobilized membrane observed (Figure 4); the peak at $3300 \mathrm{~cm}-1$ was due to the presence of amide linkage of peptide bonding $(\mathrm{NH}$ stretching), the absorption band at 1655 is for the amide I region which is due to $\mathrm{C}=0$ stretching of peptide linkage. The peaks observed at 1494 and 1229 are due to CN stretching and $\mathrm{NH}$ bending (Kong and Yu 2007).

\section{SCANNING ELECTRON MICROSCOPY (SEM)}

The SEM micrographs of AuNP tagged antigen bound with the corresponding antibody immobilized on the membrane was depicted in figure 6 at $2500 \mathrm{KX}$ magnification at a voltage of about $15 \mathrm{KV}$ (Fig. 5).

\section{MEASUREMENT OF IMPEDANCE BY ELECTROCHEMICAL BIOSENSOR}

Different sets of membranes of different pore size viz. 30, 50 and $100 \mathrm{~nm}$; simple membrane, gold-coated membrane, gold-coated thiolated, antibody immobilized

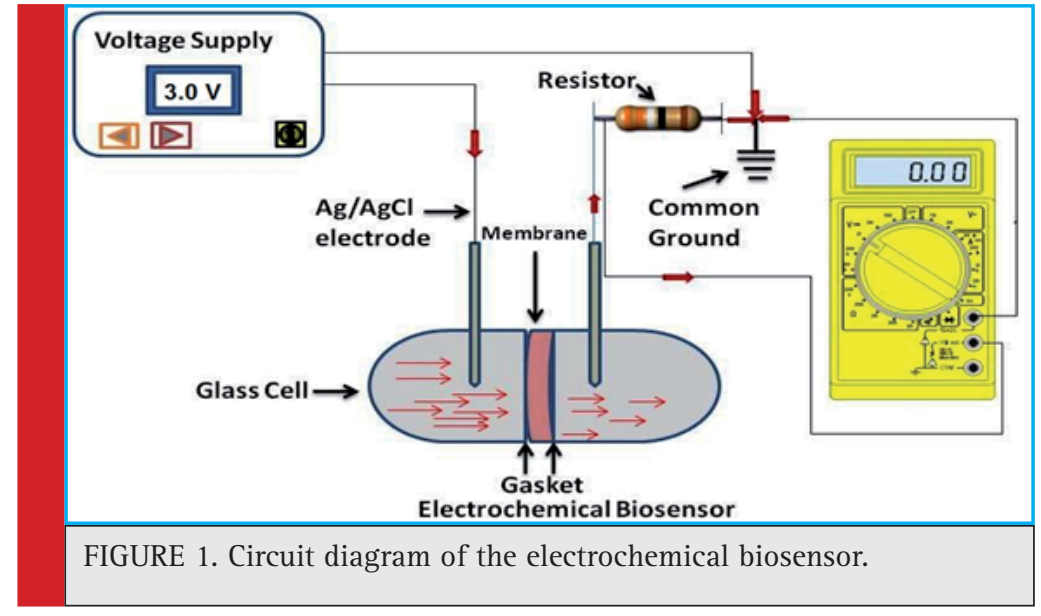




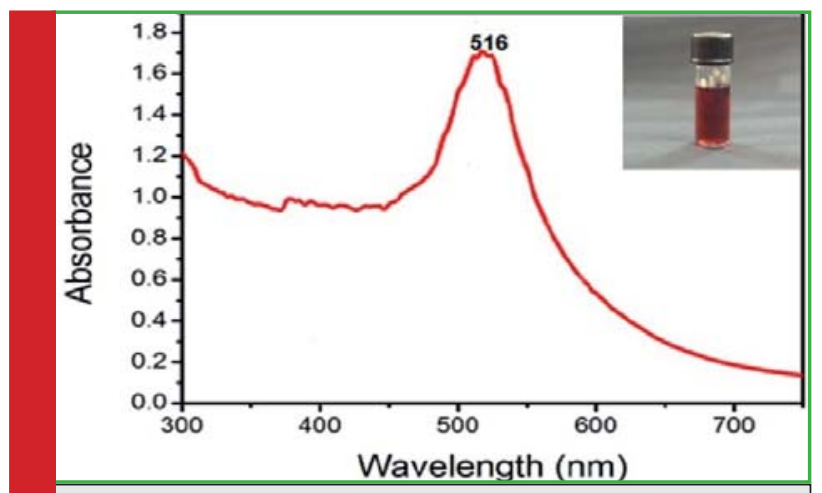

FIGURE 2. UV-Visible spectra of gold nanoparticles.

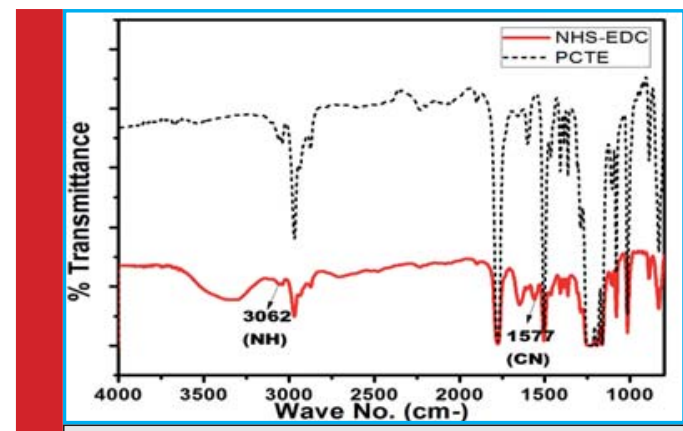

FIGURE 3. FTIR spectrum of thiolated and plane PCTE membrane membrane, membrane immobilized with corresponding $\mathrm{Ag}-\mathrm{Ab}$, membrane immobilized with corresponding gold coated $\mathrm{Ag}-\mathrm{Ab}$ and gold coated membrane immobilized with non-corresponding $\mathrm{Ag}-\mathrm{Ab}$ were fitted in the experimental setup and measurements were taken one by one in electrochemical biosensor. The setup was used to measure the potential (in volts) across $1 \mathrm{~K} \Omega$ resistance with applied potential of $3 \mathrm{~V}$ at room temperature (Fig. $6 a, b$ and $c)$.

By using the formula of impedance, the values of impedance across the different membrane was calculated using the values of potential measured after every 30 seconds of the time interval, resistance and applied potential. It is evident from the graph that the values of impedance (in $\mathrm{K} \Omega$ ) changes with time and with the modification of membrane.

Figures 7, 8 and 9 shows the change in impedance from surface modification of membrane to detection of 30, 50 and $100 \mathrm{~nm}$ of gold coated polycarbonate membrane respectively.After the gold coated membrane was functionalized with MHDA, the electron transfer across the membrane surface was reduced due to negatively charged carboxylic groups which cause repulsion while the impedance of plane polycarbonate decreases sharply. When anti-BSA and BSA were immobilized on the membrane surface, the impedance was increased again. In the case of $30 \mathrm{~nm}$, best results were obtained in comparison to 50 and $100 \mathrm{~nm}$ membrane which could be due to the larger pore size of latter. The increase in impedance after each modification increases successively indicating that

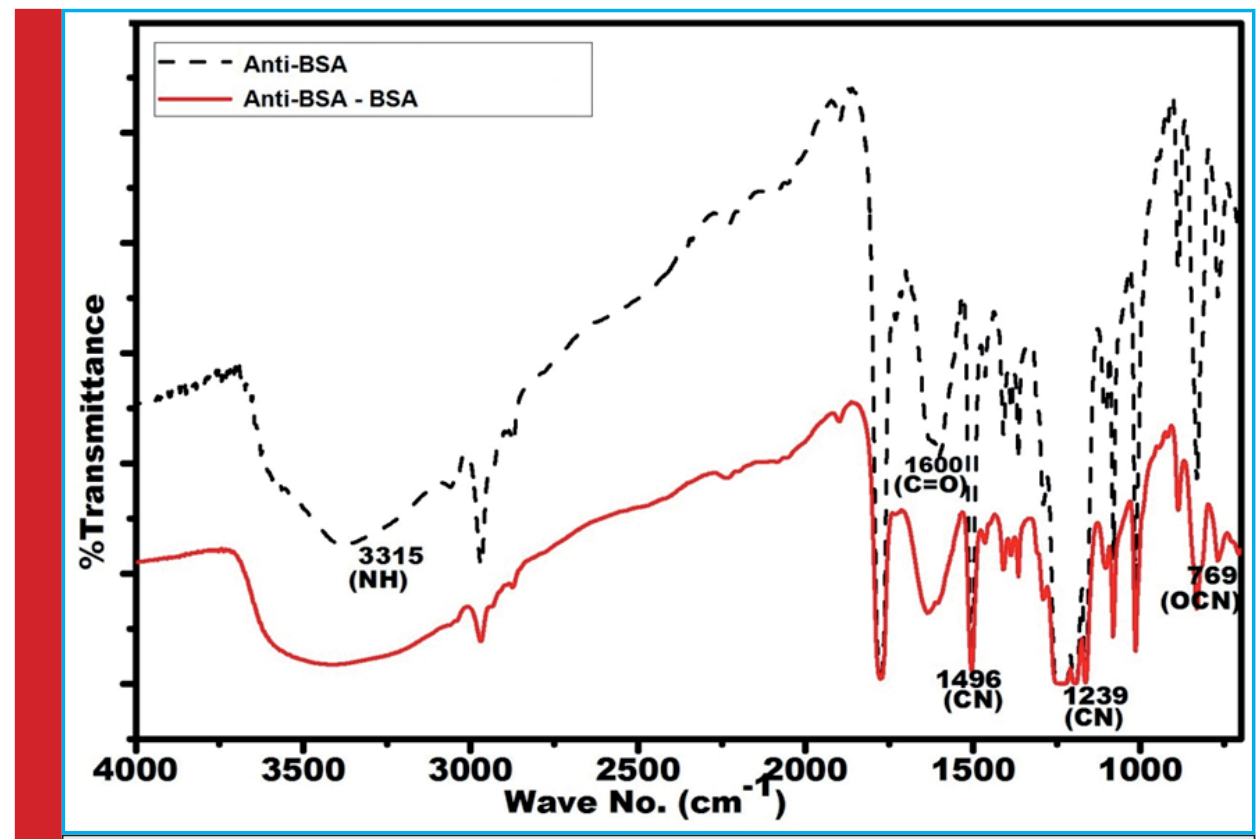

FIGURE 4. FTIR spectrum of Ab and Ag-Ab immobilized PCTE membrane. 


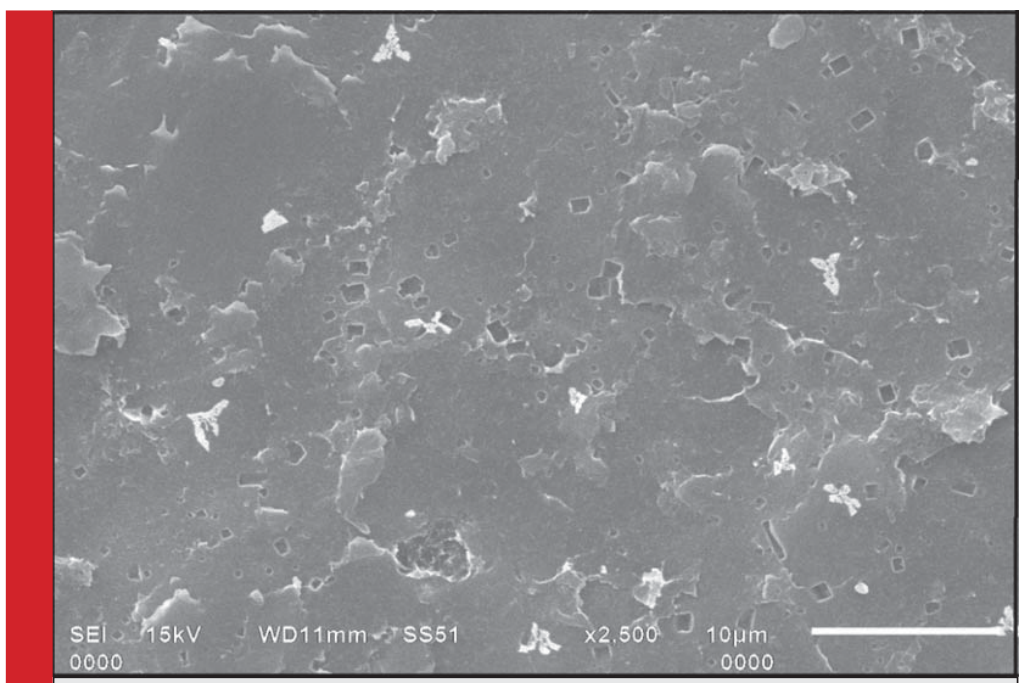

FIGURE 5. SEM Micrograph of gold coated antigen tagged with the antibody on the gold coated PCTE membrane.

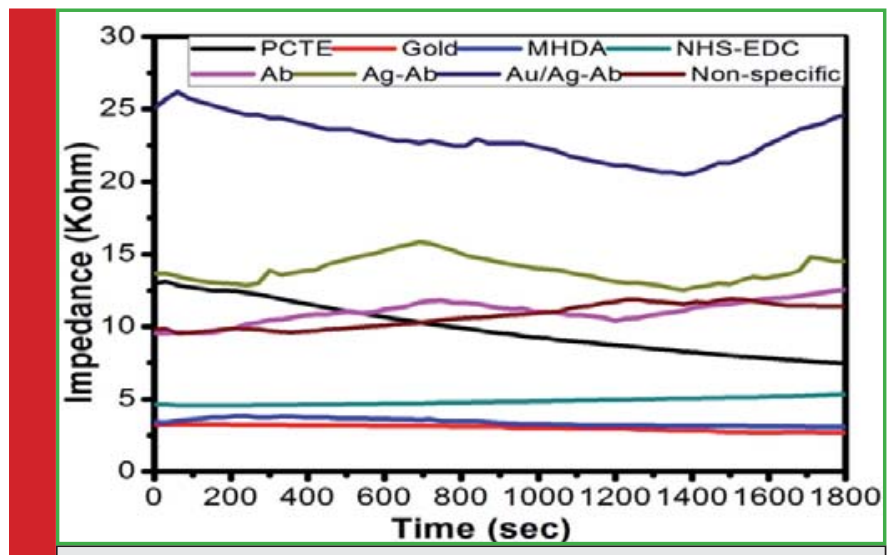

FIGURE 6a. Values of impedance with respect to time for 30 nm membrane.

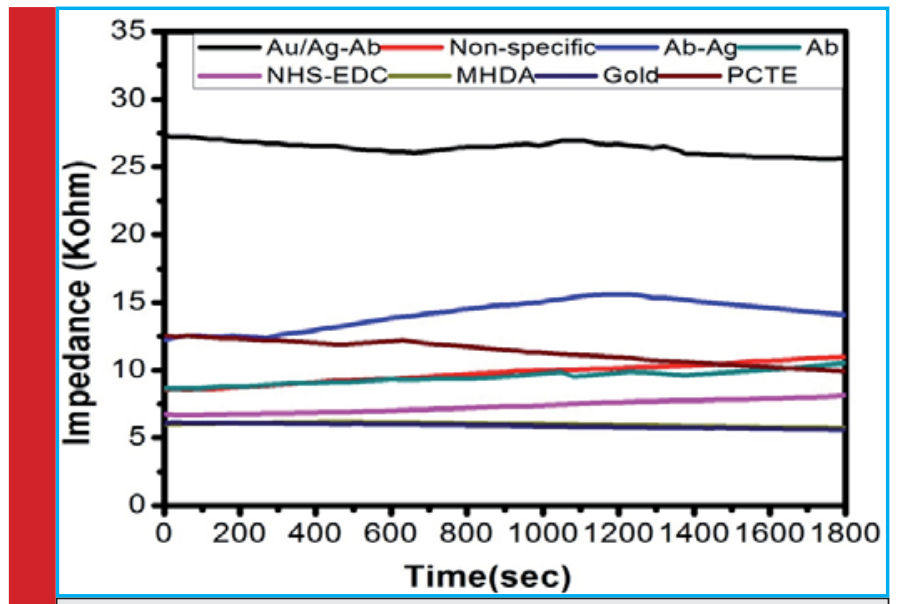

FIGURE 6b. Values of impedance with respect to time for 50 nm membrane. 


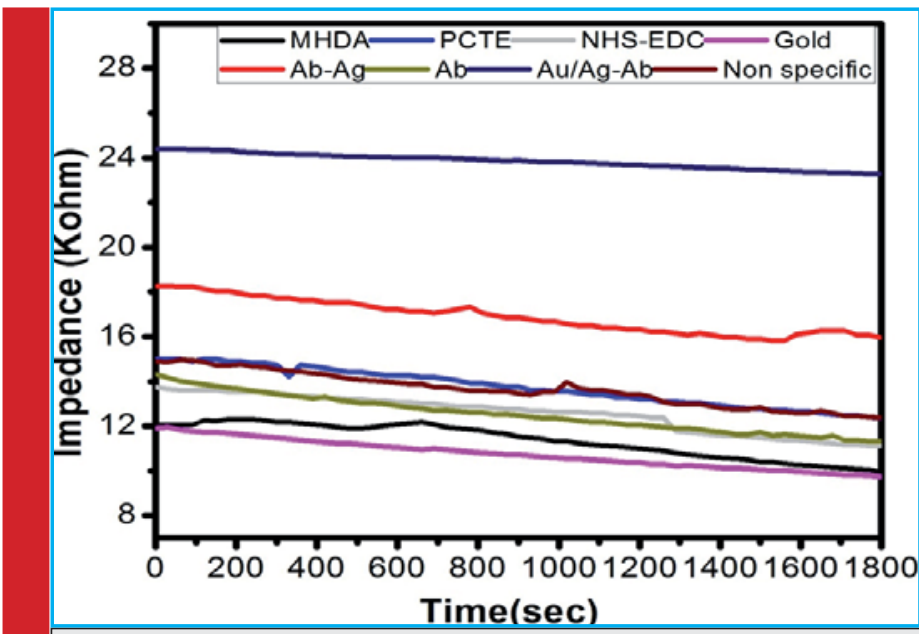

FIGURE 6c. Values of impedance with respect to time for 100 nm membrane.

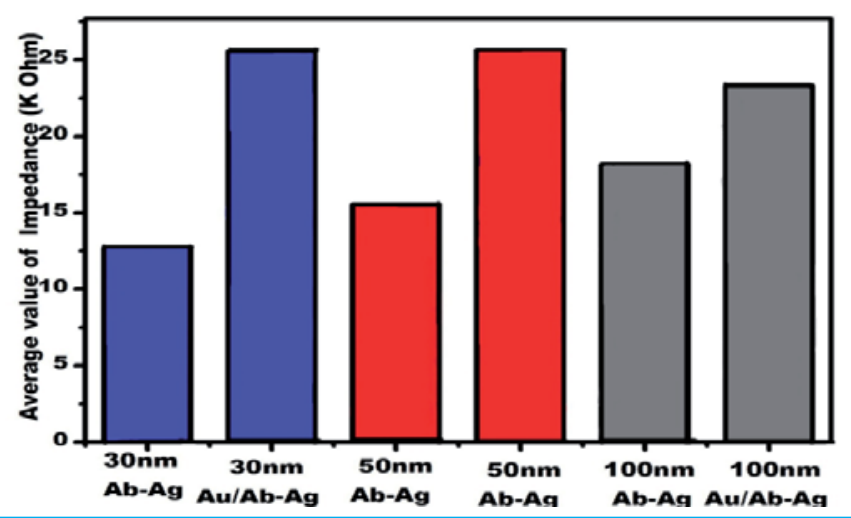

FIGURE 7. Comparison of change in impedance of antigenantibody interactions.

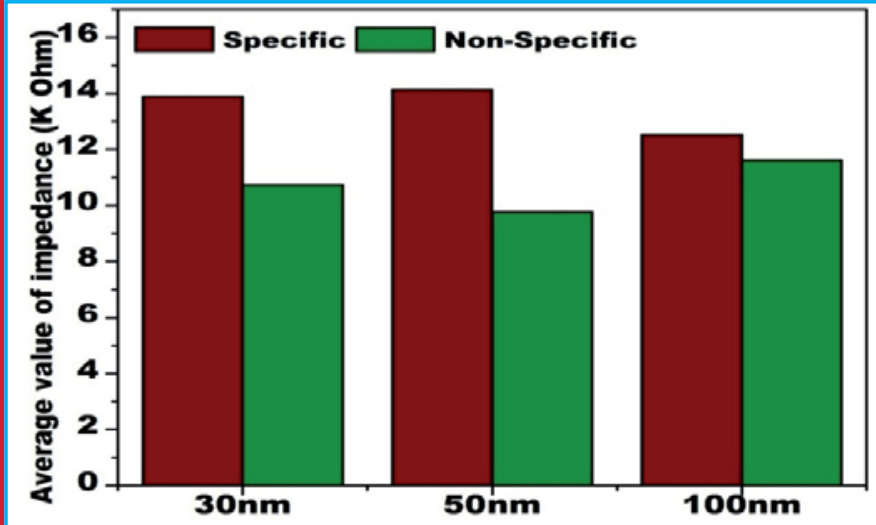

FIGURE 8. Comparison of change in impedance on non-specific antigen-antibody interactions. 
membrane was modified successfully due to a reduction in pore size resulting in increased membrane thickness. This increase between each modification step was found to be greater in the case of $30 \mathrm{~nm}$ membrane. BSA layer immobilized on the membrane might have acted as inert blocking layer hindering the diffusion of ions across the membrane and thus resulting in increased impedance (Huang et al., 2010).

For signal amplification, antigen-functionalized AuNPs (size $\sim 15 \mathrm{~nm}$, modified with a carboxy-terminated thiol and covalently coupled to the antibody through an amide bond) were utilized. The antigen-functionalized AuNPs bind to the corresponding antibody specifically which are already captured on the membrane surface. This step decreases the pore size of the surface of the membrane and leads to a further decrease in current flow. This additional decrease in pore size of the membrane due to AuNP coupled antigen results in signal amplification almost ten times than without AuNP.

The results obtained are summarized in the form of following bar graphs given below showing the comparison of the change in impedance during antigen-antibody interactions of all the three membranes viz. $30 \mathrm{~nm}$, $50 \mathrm{~nm}$ and $100 \mathrm{~nm}$.

Comparison of impedance produced by antigen-antibody interaction on gold coated polycarbonate membrane of different pore size shows that with the increase in pore size the impedance increases as shown in Figure 7. This observation could be due to partial blocking of larger pores of the membrane on protein immobilization which cannot inhibit ion movement across the membrane efficiently as compared to the lower pore sized membrane.

From the Figure 8, it is depicted that during nonspecific antigen and antibody interaction, the impedance decreases due to improper attachment as antibody lacks the binding site for non-specific antigen. On the other hand, the higher value of impedance obtained in the case of specific antigen-antibody interaction.

\section{REFERENCES}

Azzazy, H., M., and Mansour, M., M. (2009). In Vitro diagnostic prospects of nanoparticles. Clin Chim Acta.403: 1-8.

Braiek, M., Rokbani, K. B., Chrouda, A., Mrabet, B., Bakhrouf, A., Maaref, A. andJaffrezic-Renault, N.. (2012). An Electrochemical Immunosensor for Detection of Staphylococcus aureus Bacteria Based on Immobilization of Antibodies on Self-Assembled Monolayers-Functionalized Gold Electrode. Biosensors. 2: 417-426.

Cao, X., Ye, Y. and Liu, S. (2011). Gold nanoparticle-based signal amplification for biosensing. Anal Biochem. 417(1): 1-16.

Chen, X., Wang, Y., Zhou, J., Yan, W., Li, X. and Zhu, J. J. 2008. Electrochemical impedance immunosensor based on three- dimensionally ordered macroporous gold film. Anal. Chem. 80: 2133-2140.

Clark, L. C. (1962). Electrode system for continuous monitoring in cardiovascular surgery. Ann. N.Y. Acad. Sci. 148:133-153.

Crespilho, F., N., Lima, F., C., A. and da Silva, A., B., F. (2009). The origin of the molecular interaction between amino acids and gold nanoparticles: A theoretical and experimental investigation. Chem. Phys. Lett. 469: 186-190.

Grieshaber, D., MacKenzie, R., Voros, J., and Reimhult,E. (2008). Electrochemical Biosensors - Sensor Principles and Architectures. Sensors. 8: 1400-1458.

Guo, S. and Dong, S. 2009. Biomolecule-nanoparticle hybrids for electrochemical biosensors. Trends Anal Chem. 28: 96-109.

Haes, A., J., Hall, W., P., and Chang, L. (2004). A localized surface plasmon resonance biosensor: first steps toward an assay for Alzheimer's disease. Nano Lett. 4: 1029-1034.

Huang, J., Yang, G., Meng, W., Wu, L., Zhu, A. and Jiao, X.. (2010). An electrochemical impedimetricimmunosensor for label-free detection of Campylobacter Jeju Nii diarrhea patients' stool based on 0-carboxymethylchitosan surface modified $\mathrm{Fe}_{3} \mathrm{O}_{4}$ nanoparticles. Biosensors and Bioelectronics. 25: $1204-1211$.

Kleo, K., Schafer, D., Klar, S., Jacob, D., Grunow, R. and Lisdat, F. (2012). Immunodetection of inactivated Francisellatularensis bacteria by using a quartz crystal microbalance with dissipation monitoring. Anal Bioanal Chem. 404: 843-851.

Kong, J., and Yu, S. 2007. Fourier transform infrared spectroscopic analysis of protein secondary structures. ActaBiochimicaetBiophysicaSinica. 39(8): 549-559.

Li, D., Song, S., P., and Fan, C., H. (2010). Target-responsive structural switching for nucleic acid-based sensors. AccChem Res. 43: 631-641.

Lin, A., Son, D. H., Ahn, I. H., Song, G. H. and Han, W. T. (2007). Visible to infrared photoluminescence from gold nanoparticles embedded in germano-silicate glass fiber. Opt Express. 15: 6374-6379.

Lin, J., H. andJu, H., X. (2005). Electrochemical and chemiluminescent immunosensors for tumor markers. Biosens. Bioelectron., 20(8): 1461-1470.

Nykypanchuk, D., Maye, M., M., and Van der Lelie, D. 2008. DNA-guided crystallization of colloidal nanoparticles. Nature. 451: 549-552.

Omidfar, K., Khorsand, F. and Azizi, M. D. (2013). New analytical applications of gold nanoparticles as the label in antibodybased sensors. Biosensors and Bioelectronics. 43: 336-347.

Pengo, P., Baltzer, L., andPasquato, L. (2007). Substrate modulation of the activity of an artificial nano esterase made of peptide-functionalized gold nanoparticles. Angew Chem Int Ed. 46: 400-406.

Shen, X., C., Yuan, Q, and Liang, H. (2003). Hysteresis effects of the interaction between serum albumins and silver nanoparticles. Sci China. 46: 387-398. 
Singh, R. P. (2011). Prospects of Nanobiomaterials for Biosensing. Int.J Electrochem. doi.org/10.4061/2011/125487.

Song, S., P., Qin, Y., and He, Y. (2010). Functional nanoprobes for ultrasensitive detection of biomolecules. ChemSoc Rev. 39: 4234-4243.

Tang, T. C., Deng, A. and Huang, H. J. (2002). Immunoassay with a microtiter plate incorporated multichannel electrochemical detection system. Anal. Chem. 74(11): 2617-2621.

Turkevich, J., Stevenson, P. C. and Hillier, J. (1951). A study of the nucleation and growth processes in the synthesis of colloidal gold. Discuss Faraday Soc. 11: 55-75.

Vig, A., Radoi, A., Munoz-Berbel, X., Gyemant, G. and Marty, J.,L. (2009). Impedimetricaflatoxin M immunosensor based on colloidal gold and silver electrodeposition. Sensors and Actuators B. 138: 214-220.

Wang, H., Zhang, Y., Yu, H., Wu, D., Ma, H., Li, H., Du B. and Wei, Q. (2012). Label-free electrochemical immunosensor for prostate-specific antigen based on silver hybridized mesoporous silica nanoparticles. Analytical Biochemistry. 434: 123-127.

Wang, H., Castner, D. G., Ratner, B. D. and Jiang, S. (2002) Probing the orientation of

surface-immobilized immunoglobulin G by time-of-flight secondary ion mass

spectrometry. Langmuir 20: 1877-1887.

Willner, I., Baron, R. and Willner, B. 2007. Integrated nanoparticle-biomolecule systems for biosensing and bioelectronics. Biosensors Bioelectron.22: 1841-1852.

$\mathrm{Wu}$, Ching-Chou, Lin, Chia-Hung and Wang, Way-Shyan. (2009). Development of an enrofloxacinimmunosensor based on label-free electrochemical impedance spectroscopy. Talanta. 79: 62-67.

Zhu S L, Li F, Du C L, (2008)A localized surface plasmon resonance nanosensor based on rhombic Ag nanoparticle array. Sensors Actuators, 134: 193-198. 